\title{
EVALUATION AND CLINICAL USE OF EARLY WASHOUT RATIO OF THALLIUM-201 IN NORMAL AND ISCHEMIC MYOCARDIUM AFTER DIPYRIDAMOLE-INDUCED VASODILATION USING RING-TYPE EMISSION COMPUTED TOMOGRAPHY
}

\author{
Masataka Hayashi, M.D., Hirofumi Kambara, M.D., Ryuji Nohara, M.D. \\ Tetsuro Fudo M.D., Tetsuo Hashimoto, M.D., Chuichi Kawai, M.D. \\ Nagara Tamaki, M.D.*, Yoshiharu Yonekura, M.D.* \\ AND JUNJI Konishi, M.D.
}

\begin{abstract}
Using newly developed ring-type emission computed tomography (SPECT), we investigated the washout ratio (WR) of Tl-201 in the myocardium quantitatively with fast dynamic scanning after infusion of dipyridamole $(0.57 \mathrm{mg} / \mathrm{kg})$, and assessed the feasibility of early WR as a marker to detect coronary artery disease. Twenty-three patients with and 8 patients without coronary aryery disease had serial SPECT images obtained every $5 \mathrm{~min}$ for $45 \mathrm{~min}$ and at $180 \mathrm{~min}$ after dipyridamole and subsequent Tl-201 injection. The best appropriate transaxial slice was selected for WR analysis. Most appropriate diagnostic time was 25

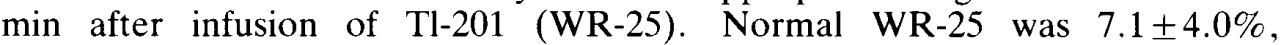
$5.9 \pm 3.1 \%$ and $7.1 \pm 2.3 \%$ at the septum, anterior and lateral wall, respectively. Sensitivity, specificity and accuracy to identify coronary stenosis $>50 \%$ with a usage of abnormal WR-25, defined as WR-25 $<$ (mean of normals $-1 \mathrm{SD}$ ) in each region of inferest of the left ventricle (LV), were $96 \%, 100 \%$ and $97 \%$, respectively. These results were better than those achieved by visual analysis (sensitivity $78 \%$, specificity $100 \%$, accuracy $84 \%$ ). In patients with single as well as multivessel disease, the regional accuracy in assessing stenosis of more than $50 \%$ in the left anterior descending artery (LAD) and left circumflex artery (LCX) by WR-25 was $94 \%$ and $83 \%$, respectively, which was significantly better than using visual methods (LAD $72 \%$ and LCX 50\%; $<<0.05$ ). Thus, evaluation of early washout ratios (WR-25) after dipyridamole injection is a valuable method to increase sensitivity in assessing regional myocardial perfusion abnormality and is helpful in detection of ischemic heart disease, even with multivessel disease.
\end{abstract}

$\mathbf{D}^{\prime \prime}$

PYRIDAMOLE is a potent vasodilator, primarily of the coronary arteries, with minor systemic effects. This potent coronary vasodilator enhances regional myocardial

Key words:

Ischemic heart disease

Dipyridamole

Ring-type single photon emission CT

Thallium-201 washout ratio

blood flow in zones supplied by normal coronary arteries but not in the myocardium perfused by obstructed vessels, producing an inhomogeneity of blood flow. Since the initial myocardial distribution of intravenous administration of Tl-201 is proportional to blood flow, 1,2 scintigraphic defects are observed demonstrating this relative

(Received February 16, 1990; accepted April 23, 1990)

Third Division, Department of Internal Medicine, and Department of Nuclear Medicine*, Kyoto University Hospital, Kyoto, Japan

Mailing address: Masataka Hayashi, M.D., Third Division, Department of Internal Medicine, Kyoto University Hospital, 54 Kawaracho, Shogoin, Sakyo-ku, Kyoto 606, Japan 


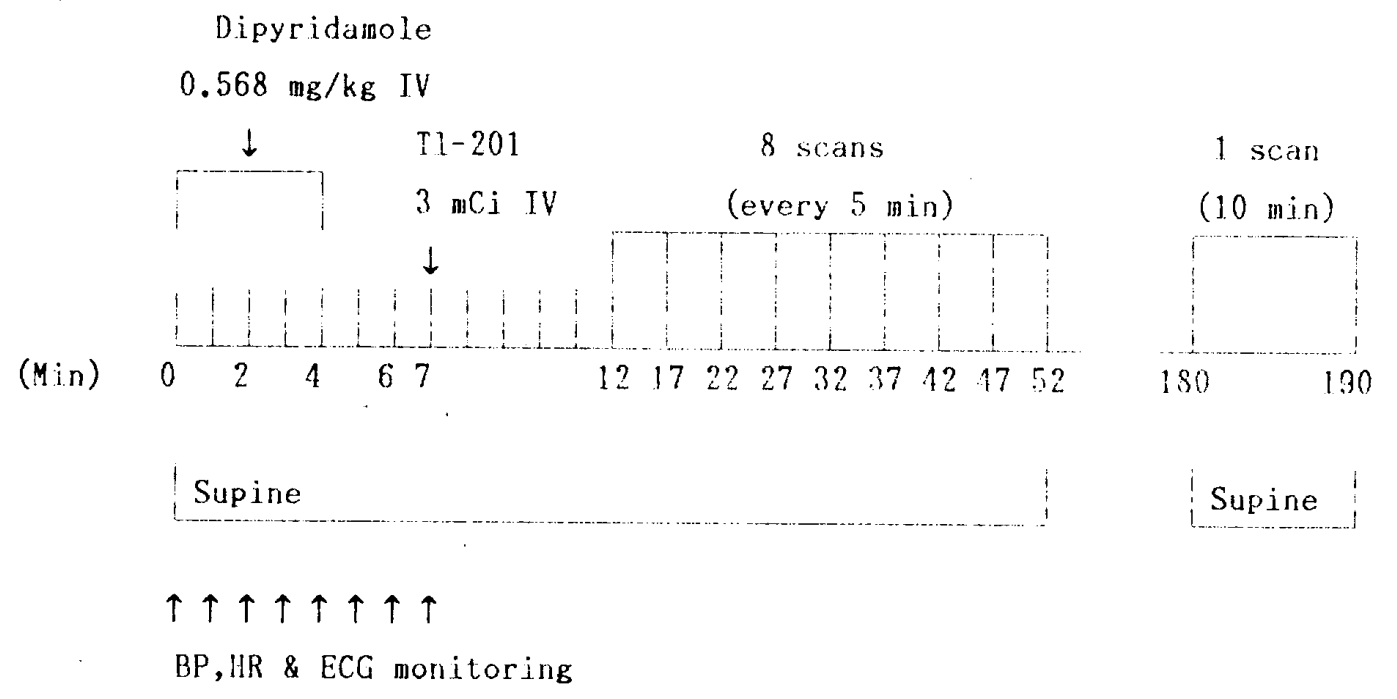

Fig.1. Protocol of thallium-201 dipyridamole imaging used for this patient study. Total dose of dipyridamole was $0.568 \mathrm{mg} / \mathrm{kg}$ over $4 \mathrm{~min}$. $\mathrm{BP}=$ blood pressure, $\mathrm{HR}=$ heart rate, $\mathrm{IV}=$ intravenously

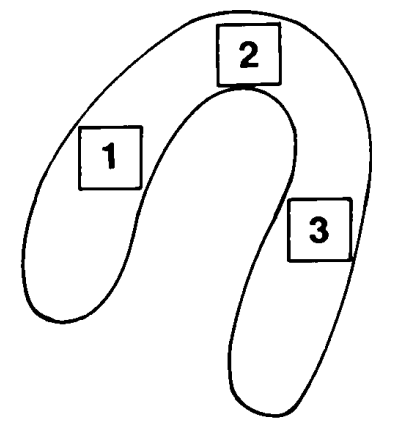

Fig.2. Schematic representation of left ventricular transaxial imaging by ring type SPECT and the ROI used for this study analysis. 1: septum, 2: anterior wall, 3: lateral wall

hypoperfusion. Intravenous infusion of dipyridamole has been suggested as an alternative to physical exercise for myocardial perfusion imaging $3-8$ This pharmacologic method is particulary useful in patients who are physically unable to perform adequate exercise, such as aged patients with peripheral vascular or musculo-skeletal disease, or those with chronic pulmonary disease. Gould et $\mathrm{al}^{3-5}$ and Albro et $\mathrm{al}^{6}$ showed that the quality of Tl-201 myocardial perfusion imaging obtained during coronary vasodilation after dipyridamole injection was equal to, or better than, that of images acquired during maximal exercise. This method is also safe because its pharmacologic effect can be completely blocked within a few seconds by intravenous administration of aminophylline? -10

Beller,1,12 Schmoliner,3 Leppo $^{14,15}$ and Okada ${ }^{16,17}$ have demonstrated that under conditions of coronary stenosis in canine preparations, dipyridamole results not only in diminished Tl-201 uptake but also in subsequently delayed redistribution similar to that observed with exercise scintigraphy. Redistribution has also been demonstrated on serial myocardial scintigrams in patients with coronary artery disease receiving dipyridamole before Tl-201 administration!1-15,18 However, the sequential process and clinical significance of Tl-201 redistribution after dipyridamole imaging are not fully elucidated. We used a ring-type emission computed tomography (SPECT) in which detectors were arranged in a circular array to achieve better counting and fast dynamic scanning, ${ }^{18,19}$ and measured the early washout ratio after dipyridamole-induced vasodilation. The purpose of the study is to assess dynamic changes of Tl-201 washout and it clinical usefulness in detecting coronary artery disease with dipyridamole administration.

\section{MATERIAL AND METHOD}

Study patients: Thirty-one consecutive patients $(21$ males and 10 females, mean age $57 \pm 10$ years, ranging from 20 to 71 years) referred for cardiac catheterization and cor- 
TABLE I CLINICAL BACKGROUNDS AND FINDINGS OF THALLIUM-201 RING TYPE SPECT IN 31 PATIENTS

\begin{tabular}{|c|c|c|c|c|c|c|}
\hline \multirow{2}{*}{ No. } & \multirow{2}{*}{ Age \& Sex } & \multicolumn{3}{|c|}{$\begin{array}{l}\text { Coronary angiography } \\
\text { (\% of diameter narrowing) }\end{array}$} & \multirow{2}{*}{ Diagnosis } & \multirow{2}{*}{ Finding of dynamic SPECT } \\
\hline & & $L A D$ & $L C X$ & $R C A$ & & \\
\hline 1. & $20 M$ & 0 & 0 & 0 & Normal & Homogenous \\
\hline 2. & $62 F$ & 0 & 0 & 0 & Normal & Homogenous \\
\hline 3. & $45 F$ & 0 & 0 & 0 & Normal & Homogenous \\
\hline 4. & $54 F$ & 0 & 0 & 0 & Normal & Homogenous \\
\hline 5. & $57 F$ & 0 & 0 & 0 & Normal & Homogenous \\
\hline 6. & $29 M$ & 0 & 0 & 0 & Synd $X$ & Homogenous \\
\hline 7. & $70 F$ & 0 & 0 & 0 & Synd $X$ & Homogenous \\
\hline 8. & $63 F$ & 0 & 0 & 0 & Synd $X$ & Homogenous \\
\hline 9. & $62 M$ & $7-90$ & 0 & 0 & $A P$ & Hypoperfusion (Antero-septal) \\
\hline 10 & $72 F$ & 90 & 0 & 90 & $A P$ & Hypoperfusion (Aniero-septal) \\
\hline 11. & $59 M$ & 99 & 90 & $\ddot{\theta}$ & $A P$ & Hypoperfusion (Aniero-septal) \\
\hline 12. & $55 M$ & 50 & 0 & 0 & $A P$ & Homogenous \\
\hline 13. & $57 M$ & 50 & 50 & 0 & $A P$ & Hypoperfusion (Postero-lateral) \\
\hline 14 & $59 M$ & 90 & 99 & 25 & $A P$ & Hypoperfusion (Anterior) \\
\hline 15. & $60 M$ & 0 & 90 & 75 & $A P$ & Hypoperfusion (Postero-lateral) \\
\hline 16. & $69 F$ & 0 & 90 & 0 & $A P$ & Homogenous \\
\hline 17. & $66 F$ & 75 & 75 & 75 & $A P$ & Homogenous \\
\hline 18. & $59 M$ & 50 & 0 & 0 & $A P$ & Homogenous \\
\hline 19. & $40 M$ & 99 & 0 & 0 & $A P$ & Hypoperfusion (Antero-septal) \\
\hline 20 & $55 M$ & 50 & 90 & 75 & $M I$ & Homogenous \\
\hline 21. & $71 M$ & 90 & 0 & 50 & $M I$ & Perfusion defect (Antero-septal) \\
\hline 22. & $46 M$ & 99 & 90 & 50 & $M I$ & Perfusion defect (Antero-septal) \\
\hline 23. & $57 M$ & 99 & 100 & 99 & $M I$ & Perfusion defect (Postero-lateral) \\
\hline 24. & $64 M$ & 90 & 100 & 75 & $M I$ & Perfusion defect (Postero-lateral) \\
\hline 25. & $63 M$ & 99 & 99 & 50 & MI & Perfusion defect (Antero-septal) \\
\hline 26. & $65 M$ & 90 & 0 & 0 & $M I$ & Perfusion defect (Antero-septal) \\
\hline 27. & $59 M$ & 90 & 50 & 0 & $M I$ & Perfusion defect (Antero-septal) \\
\hline 28. & $57 M$ & 90 & 50 & 25 & $M I$ & Perfusion defect (Antero-septal) \\
\hline 29. & $63 F$ & 99 & 25 & 25 & $M I$ & Perfusion defect (Antero-septal) \\
\hline 30 & $53 M$ & 0 & 90 & 0 & $M I$ & Perfusion defect (Postero-lateral) \\
\hline 31. & $55 M$ & 50 & 0 & 100 & $M I$ & Homogenous \\
\hline
\end{tabular}

$A P=$ angina pectoris, $M I=$ myocardial infarction, $L A D=$ left anterior descending artery,

$L C X=$ left circumflex artery, $R C A=$ right coronary artery, Synd =syndrome

nary angiography for evaluation of chest pain were studied. They were classified into two subgroups: 8 patients with no coronary artery disease $(2$ males and 6 females, mean age $50 \pm 18$ years) and 23 patients with coronary artery disease (19 males and 4 females, mean age $59 \pm 7$ years). Of 23 patients with coronary artery disease, 12 had a history of myocardial infarction.
Coronary angiography: Coronary artery desease was difined as $>50 \%$ luminal narrowing in diameter of one or more major coronary arteries or their major branches. The finding had to be confirmed by more than 5 experienced observers who were unaware of the thallium scintigraphic findings. The major branches included 1) the first diagonal branch of the left anterior descending 


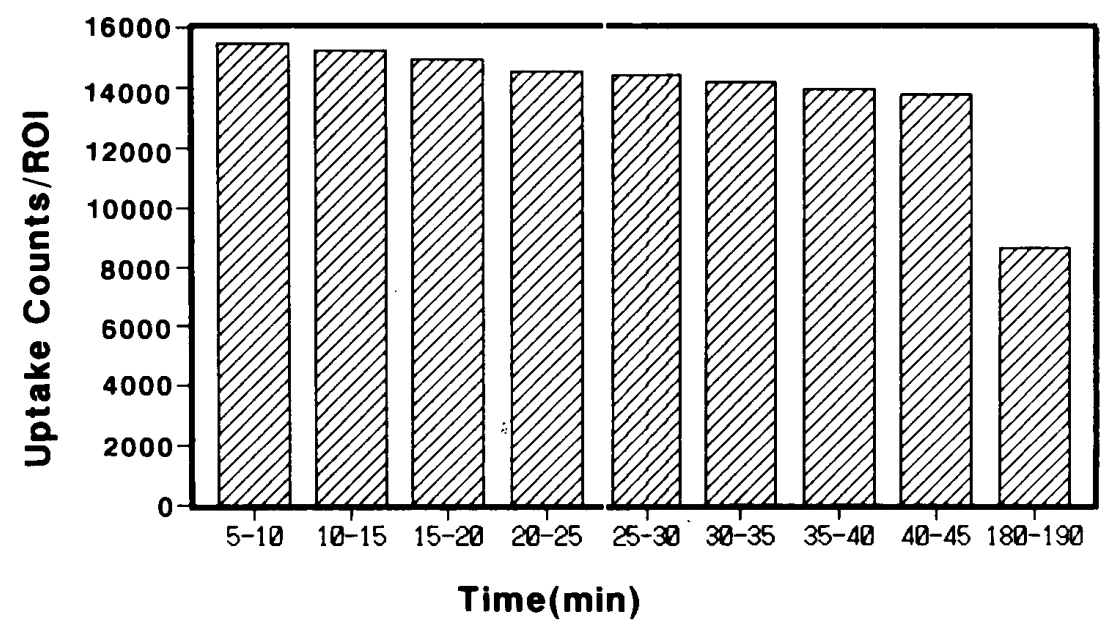

Fig.3. Serial uptake counts at the ROI of left ventricular slice of normal patients. Initial uptake counts $(5-10 \mathrm{~min})$ of the normal ROI were the highest and decreased gradually with time.

TABLE II SERIAL WASHOUT RATIO OF THALLIUM-201 OVER THE LEFT VENTRICLE IN 8 NORMAL PATIENTS

\begin{tabular}{ccccccccc}
\hline \hline & $t=10$ & $t=15$ & $t=20$ & $t=25$ & $t=30$ & $t=35$ & $t=40$ & $t=180$ \\
& $(10-15)$ & $(15-20)$ & $(20-25)$ & $(25-30)$ & $(30-35)$ & $(35-40)$ & $(40-45)$ & $(180-190)$ \\
\hline Septum & & & & & & & & \\
mean $\pm S D$ & $1.8 \pm 3.3$ & $3.8 \pm 1.8$ & $5.7 \pm 2.5$ & $7.1 \pm 4.0$ & $10.1 \pm 3.3$ & $10.7 \pm 5.8$ & $12.7 \pm 6.5$ & $44.0 \pm 6.4$ \\
mean-SD & -1.5 & 2.0 & 3.2 & 3.0 & 6.8 & 4.9 & 6.2 & 37.6 \\
Anterior wall & & & & & & & & \\
$\quad \begin{array}{l}\text { mean } \pm S D \\
\text { mean-SD }\end{array}$ & $1.4 \pm 4.4$ & $2.8 \pm 3.0$ & $6.5 \pm 3.7$ & $5.9 \pm 3.1$ & $8.3 \pm 4.6$ & $9.7 \pm 8.6$ & $10.6 \pm 7.9$ & $43.5 \pm 7.1$ \\
Lateral wall & -3.0 & -0.3 & 2.8 & 2.8 & 3.7 & 1.1 & 2.7 & 36.4 \\
$\quad$ mean $\pm S D$ & $1.1 \pm 1.6$ & $3.5 \pm 4.3$ & $6.1 \pm 2.8$ & $7.1 \pm 2.3$ & $7.3 \pm 4.5$ & $9.3 \pm 5.2$ & $8.7 \pm 4.0$ & $42.8 \pm 4.2$ \\
mean-SD & -0.5 & -0.8 & 3.3 & 4.8 & 2.8 & 4.1 & 3.7 & 38.6 \\
Global & $1.5 \pm 3.1$ & $3.4 \pm 3.1$ & $6.1 \pm 3.0$ & $6.7 \pm 3.1$ & $8.6 \pm 4.1$ & $9.9 \pm 6.5$ & $10.7 \pm 6.2$ & $43.4 \pm 5.9$ \\
mean-SD & -1.6 & 0.3 & 3.1 & 3.6 & 4.5 & 3.4 & 4.5 & 37.5 \\
\hline
\end{tabular}

$t=$ Starting time of acquistion, $(\quad)=($ interval $)$

artery, 2) obtuse marginal branch of the left circumflex artery, and 3) posterior descending branch of the right coronary artery with right dominant system, or left circumflex artery with left dominant system.

Ring-type emission computed tomography: The ring-type emission computed tomography scanner (SET-030W, Shimazu) had 128 detectors of $14 \times 24 \times 30 \mathrm{~mm} \mathrm{NaI}$ crystal arranged in a circular array of $660 \mathrm{~mm}$ in diamenter. There were three detector rings at $30 \mathrm{~mm}$ intervals and total of 384 detectors in a gantry. A high resolution collimator was used. Spatial resolution at the center of the eye field was $14.2 \mathrm{~mm}$ and slice thickness was $24 \mathrm{~mm}$. The sensitivity was measured using cylindrical phantoms containing ${ }^{99} \mathrm{mTc}$. The sensitivity for a $20 \mathrm{~cm}$ diameter phantom was $5700 \mathrm{cps} / \mathrm{mCi} / \mathrm{ml}$. Acquisition was performed for 5 or $10 \mathrm{~min}$. Image reconstruction was made using the back projection method with a Shapp-Logan filter using a convolution reconstruction algorithm. Acquisition time correction was performed without attenuation correction.

Thallium-201 imaging with dipyridamole administration: The imaging protocol (Fig. 1) is a modification of the technique described by Albro et al. At the beginning of the study, the patient laid supine on a tilt 


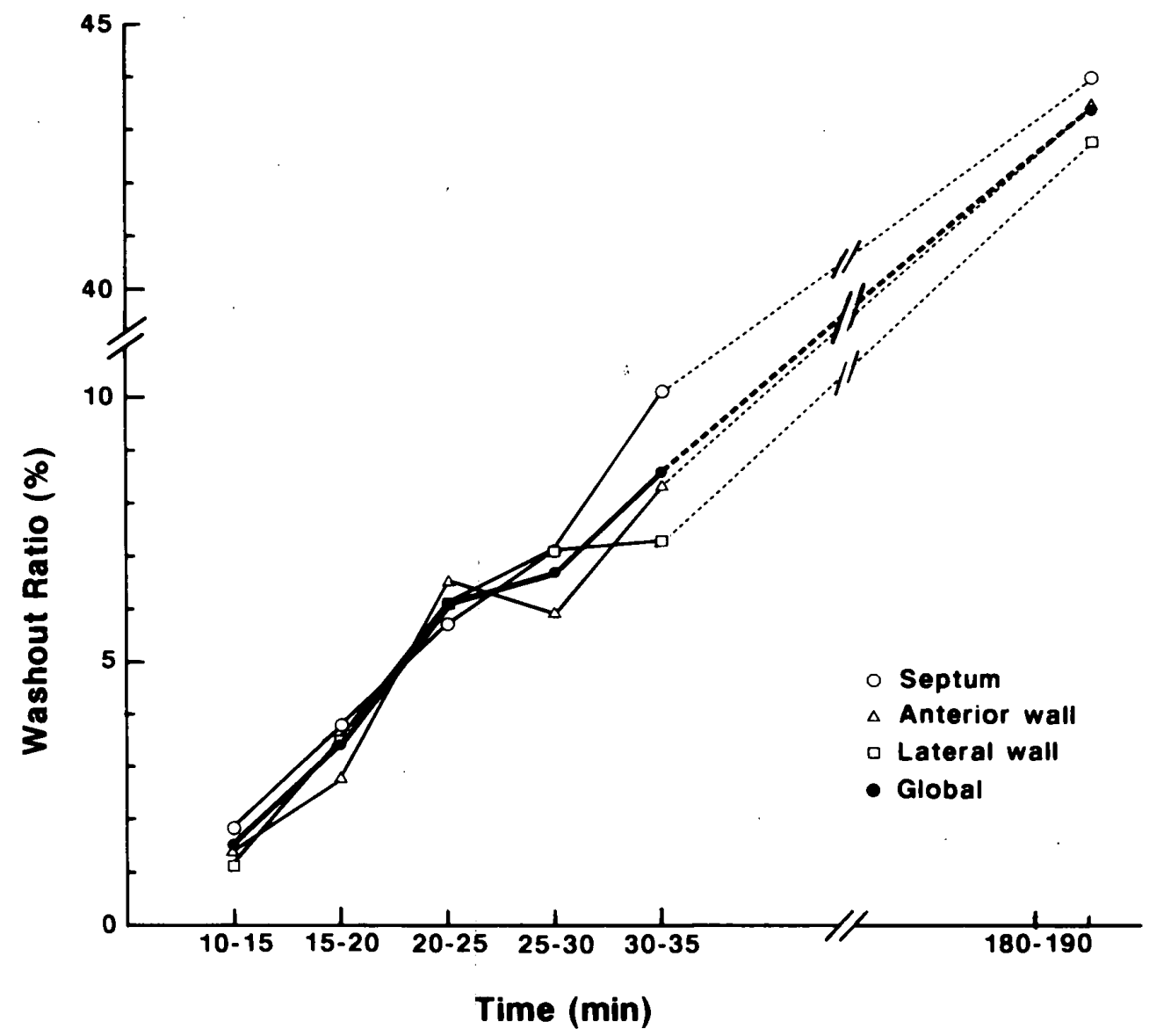

Fig.4. Serial washout ratio of thallium-201. Serial change of washout ratio in each segment was essentially similar with a linear relationship.

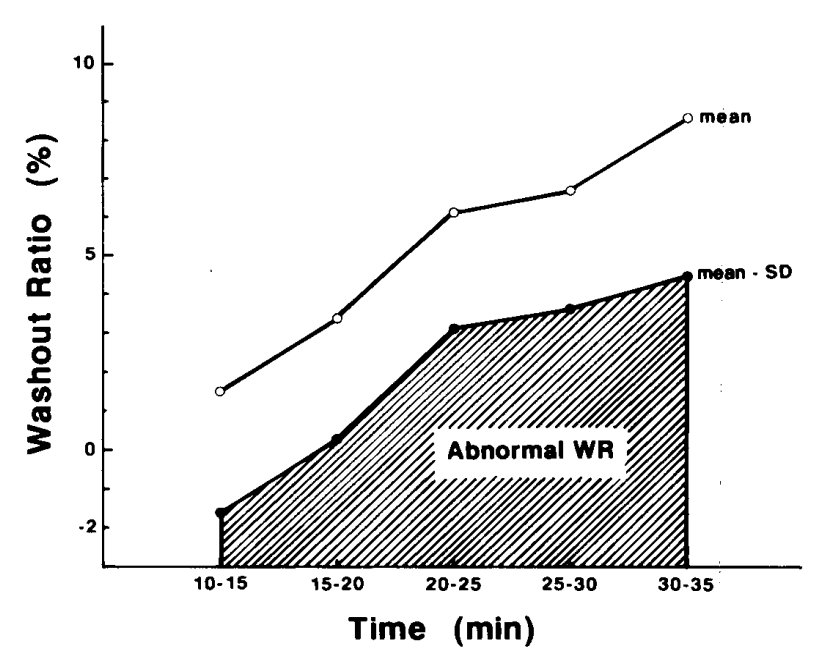

Fig.5. Serial washout ratio of thallium-201. Hatched part is an area defined as abnormal washout ratio.

table. A 23-gauge plastic cannula was placed in a large antecubial vein to avoid pain due to dipyridamole injection into the small vein.
A 12-lead ECG was recorded during the study. Blood pressure by a cuff method and heart rate were monitored every minute during the study period. Dipyridamole (Boehringer Ingelheim Co.) was then infused with a total dose $0.568 \mathrm{mg} / \mathrm{kg}$ over 4 min. Side effects due to dipyridamole injection, such as chest pain, nausea or vomiting were suppressed with $125 \mathrm{mg}$ of intravenous aminophylline. Seven minutes after starting dipyidamole infusion, $3 \mathrm{mCi}$ of thallium-201 (JAPAN Mediphysics Co.) was injected through the 23-gauge plastic canula. Data acquisition was performed from 5 to $45 \mathrm{~min}$ after injection, followed by additional scan at $180 \mathrm{~min}$ after injection. Each acquisition time was $5 \mathrm{~min}$ from the first to the eighth acquisition and $10 \mathrm{~min}$ in the ninth acquisition. Body positioning in the gantry was carefully set with a marker on the body and a light beam from the gantry to avoid mispositioning. All patients were in a fasting state until delayed imaging was taken. 
TABLE III COMPARATIVE ANALYSIS OF SERIAL WASHOUT RATIO

\begin{tabular}{lccccc}
\hline \hline & WR-20 & WR-25 & WR-30 & WR-35 & WR-40 \\
\hline Sensitivity (\%) & 96 & 96 & 96 & 78 & 91 \\
Specitivity (\%) & 75 & 100 & 100 & 100 & 87 \\
Accuracy (\%) & 90 & 97 & 97 & 84 & 90 \\
\hline
\end{tabular}

The sensitivity specificity and accuracy of WR-25 were $96 \%, 100 \%$ and $97 \%$, respectively, and WR-25 was more accurate than the WR of other reference times.

$W R-t$ : Washout ratio during to $t+5 \mathrm{~min}$.

TABLE .VI COMPARISON BETWEEN VISUAL ASSESSMENT AND ANALYSIS OF WASHOUT RATIO

\begin{tabular}{|c|c|c|c|c|c|c|}
\hline & \multicolumn{2}{|c|}{ LAD } & \multicolumn{2}{|c|}{ LCX } & \multicolumn{2}{|c|}{$\mathrm{LAD}+L C X$} \\
\hline & Visual & $W R-25$ & Visual & $W R-25$ & Visual & $W R-25$ \\
\hline Sensitivity (\%) & 72 & 94 & 50 & 93 & 78 & 96 \\
\hline Sensitivity (\%) & 100 & 85 & 100 & 82 & 100 & 100 \\
\hline Accuracy (\%) & 84 & 90 & 84 & 87 & 84 & 97 \\
\hline
\end{tabular}

Sensitivity, specificity and accuracy of washout ratio analysis were better than those of visual analysis.

WR-25: Washout ratio during 25 to $30 \mathrm{~min}$.

Qualitative analysis of serial Tl-201 images: Serial transaxial thallium-201 images were displayed on a computer screen for comparison. The visual analysis was carried out by more than three independent investigators who were unaware of the findings of cardiac catherization or the patient's clinical history. The myocardial segments were matched according to the coronary artery distribution as follows: septum and anterior segments corresponded to the left anterior descending coronary artery and a lateral segment to left circumflex artery or diagonal branch. Because only transaxial images were reconstructed, an inferior segment was not evaluated. The visual results were interpreted by the consensus of all investigators.

Quantitative analysis of serial $\mathrm{Tl}-201 \mathrm{im}$ ages: We analyzed a tomographic slice of most appropriate transaxial image in each patient. The left ventricular wall of this image was divided into 3 segments (Fig. 2). A region of interest (ROI) was set at the septum, anterior wall and lateral wall of the left ventricle. Each ROI contained 81 pixels. A washout ratio at each time interval was calculated as follows:

Washout ratio $($ WR-t $)=\frac{\mathrm{Ci}-\mathrm{Ct}}{\mathrm{Ci}} \times 100(\%)$

Japanese Circulation Joumal Vol.55, March 1991 where $\mathrm{t}$ is the starting time of acquisition, $\mathrm{Ct}$ is the counts of each ROI at the time of acquisition and $\mathrm{Ci}$ is the counts of the ROI at initial time of acquisition. The abnormal range of thallium washout ratio was defined as less than $1 \mathrm{SD}$ from the mean value obtained from normal patients group.

Statistcal analysis: Sensitivity was difined as the (true positive $\times 100) /($ true positive + false negative); specificity as (true negative $\times 100) /($ true negative + false positive $)$; and accuracy as (true positive + true negative)/ (total number of cases). A p value less than 0.05 was considered to be statistically significant with Student's t test, and all values were expressed as mean $\pm 1 \mathrm{SD}$.

\section{RESULTS}

Coronary angiographic findings (Table I): Angiographically significant coronary artery stenosis of at least one major coronary artery was present in 23 of the 31 patients. Eight patients had angiographically normal coronary arteries without any provocative spasm. Of the 23 patients with significant coronary artery disease, 8 had single vessel disease, 9 had double vessel disease and 6 triple vessel disease. 

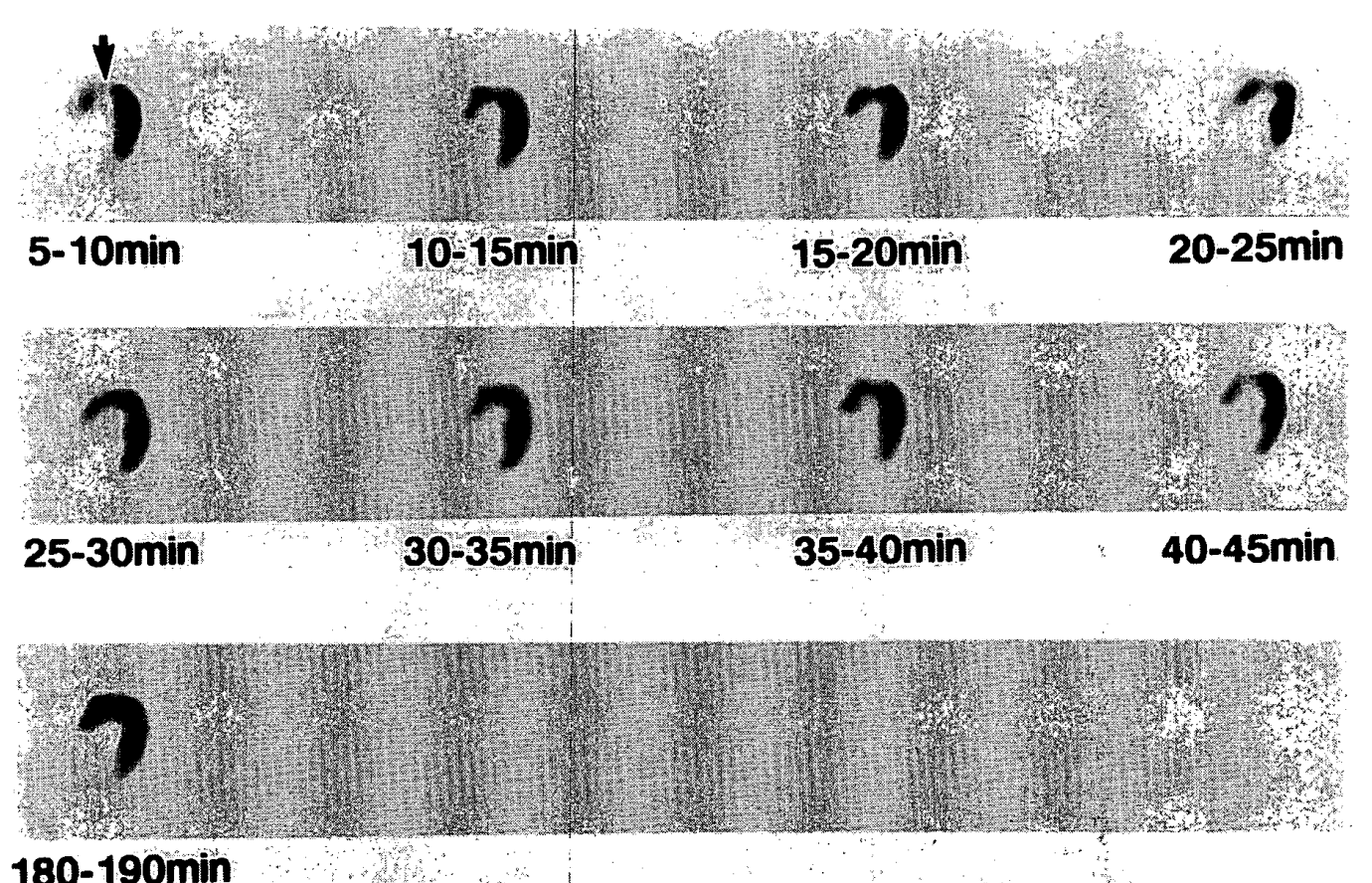

180-190min

Fig.6. A representative serial thallium scintigraphy of ring type SPECT. An antero-septal hypoperfusion is recognizable in the initial image (5-10 min: arrow) and persist until the 8th imaging (40-45 $\mathrm{min})$ with slight reperfusion. However, complete reperfusion was seen in the last imaging (180-190 $\mathrm{min})$.

Hemodynamic response to dipyridamole: Changes in heart rate, systolic blood pressure and diastolic blood pressure after dipyridamole infusion were significant but small. The heart rate before infusion of dipyridamole was $67 \pm 12$ beats/min and increased to $77 \pm 14$ beats/min in 4 min after dipyridamole $(\mathrm{p}<0.001)$, and to $81 \pm 14$ beats $/ \mathrm{min}$ in $7 \mathrm{~min}$ $(\mathrm{p}<0.001)$. The systolic blood pressure before infusion of dipyridamole was $126 \pm 18$ $\mathrm{mmHg}$ and fell to $113 \pm 20 \mathrm{mmHg}$ in $4 \mathrm{~min}$ after dipyridamole $(\mathrm{p}<0.001)$ and $111 \pm 20$ $\mathrm{mmHg}$ in $7 \mathrm{~min}(\mathrm{p}<0.001)$. The diastolic blood pressure before dipyridamole was $77 \pm 13 \mathrm{mmHg}$ and fell to $68 \pm 13 \mathrm{mmHg}$ in 4 min after dipyridamole $(\mathrm{p}<0.001)$ and $66 \pm$ $12 \mathrm{mmHg}$ in $7 \mathrm{~min}(\mathrm{p}<0.001)$.

Adverse effects of dipyridamole: Eight of 31 patients experienced some complaints or adverse effects. Three patients complained of chest pain, usually mild to moderate in intensity and of quality similar to that of angina previously experienced on effort. The chest pain was promptly relieved by the intravenous administration of aminophylline (average dose $125 \mathrm{mg}$ ) in all patients. Ischemic ECG changes occurred in 3 patients, and only 1 of 3 patients had chest pain. Other symptoms included palpitation (1 patient), dizziness (1 patient) and dyspnea (1 patient).

Serial washout ratio of thallium-201: Fig. 3 shows serial uptake counts after Tl-201 injection in the normal ROI. The initial uptake counts $(5-10 \mathrm{~min})$ of the normal ROI were the highest counts and decreased gradually. In Table II, the serial washout ratio of Tl201 over the left ventricle in 8 normal patients is shown. The mean washout ratios of the septum, anterior wall and lateral wall at each time were calculated. A serial change of washout ratio in each segment was essentially identical with a linear relationship (Fig. 4), so that we used the global mean washout ratio to assess ischemia. Abnormal washout ratio defined as $\mathrm{WR}<$ (mean of normal -1 SD) at each time period (Fig. 5) gave the sensitivity, specificity and accuracy to detect coronary stenosis $>50 \%$ as summarized in Teble III. The sensitivity, specificity and accuracy of washout ratio at $25 \mathrm{~min}$ (WR-25) were $96 \%, 100 \%$ and $97 \%$ (Table III), respectively. Because accuracy at $25 \mathrm{~min}$ was better than that at any other reference time, WR-25 was selected to diagnose ischemic heart disease. Table IV showed a comparison between visual assessment and analysis 
of washout ratio. Sensitivity, specificity and accuracy in the assessment of stenosis of the left anterior descending artery by WR-25 were $94 \%, 85 \%$ and $90 \%$, respectively, which was significantly better than visual analysis (sensitivity 72\%, specificity 100\% and accuracy $84 \%$ ). Sensitivity, specificity and accuray in assessment of stenosis of the left circumflex artery by WR-25 were $93 \%$, $82 \%$ and $87 \%$, respectively, which was significantly better than visual analysis (sensitivity $50 \%$, specificity $100 \%$ and accuracy $84 \%$ ). Sensitivity, specificity and accuracy in assessment of stenosis of combined LAD and LCX artery by WR-25 were $96 \%, 100 \%$ and $97 \%$, respectively, which was significantly better than visual analysis (sensitivity $78 \%$, specificity $100 \%$ and accuracy $84 \%$ ).

$A$ representative case of angina pectoris: Thallium-201 scintigraphy with the ring-type SPECT in a 40 year old man is shown in Fig. 6 . The patient had effort angina and single vessel disease of the left anterior descending coronary artery. An antero-septal hypoperfusion is recognizable in the initial imaging (5-10 min) and persisted until the 8th imaging (40-45 min) with minimal reperfusion, but complete reperfusion was seen in the last imaging (180-190 min).

\section{DISCUSSION}

$A$ ring-type emission $C T$ : Emission computed tomography is more reliable than planar imaging. However, conventional emission computed tomography using a rotating gamma camera has a relatively low count sensitivity, and requires a substantial amount of time for acquisition. For this reason, it is not suitable for evaluating the early distribution of Tl-201 and time course of washout after tracer injection. With ring-type emission computed tomography, multiple detectors are placed in a circular array, giving a better counting rate so that it is possible to acquire data in a short time and to perform dynamic studies. In our current study, one scan could be performed in five minutes by rotating the detector $360^{\circ}$.

Kinetics of the thallium-201 with dipyridmole: The regional myocardial uptake of Tl201 has been shown to be an accurate representation of regional perfusion, $1,20-22$ and the quantitative relationship between global left ventricular Tl-201 uptake and blood flow has been examined by Melin et al and Beller et al $11,12,23$ In a canine model, intravenous dipyridamole causes a disparate rate of thallium uptake in normal vessels and stenosed vessels $!^{1,12}$ Myocardial thallium uptake is related to the regional and transmural difference in the coronary blood flow. In the normal zone, there is a fourfold increase in both endocardial and epicardial coronary blood flow, while in the stenosed vessel the total flow may not change although the epicardial flow may increase slightly while the endocardial flow decreases. The relative decrease of thallium uptake in the area of the stenosed vessel correlates well with the decrease of coronary flow relative to the peak flow in the normal area. In addition to initial differences of thallium activity, there are also differences in washout rates between the area perfused with normal vessels and stenosed vessels. The washout is much slower in the area perfused with stenosed vessels. The average time of maximal thallium uptake obtained from the biopsies was $8.4 \pm 1.4 \mathrm{~min}$ after dipyridamole injection in a canine model 11,23 In our current study, the average time of maximal thallium uptake obtained from the dynamic SPECT was 5-10 min in the normal coronary myocardium, but was delayed to $30 \mathrm{~min}$ in the myocardium with the stenosed coronary artery. The counts at regions of myocardial infarction were lower than those of angina pectoris. This may suggest that the low thallium-201 uptake in an infarcted region is associated not only with the severity of coronary artery stenosis but also with low viable myocardium. On the other hand, the washout ratios of both myocardial infarction and angina pectoris with severe stenosis were slower than those of normal regions according to our data. The disparate rates of washout between normal and abnormal zones account for the differences in redistribution of thallium uptake between these two areas. Similar findings have been reported when the intrinsic washout was studied by direct intracoronary injection of Tl-201!2 A few of the stenosed areas showed no hypoperfusion on the early visual imaging, especially in patients with multivessel disease, but the serial washout ratio was lower than that of the normal area, so that the washout analysis provided better 
accuracy than visual analysis.

Sensitivity and specificity: Previous clinical studies have suggested the value of thallium201 imaging for evaluating regional blood flow during pharmacological vasodilation?,15,17 Sensitivities of $67-91 \%$ and specificities of $80-100 \%$ have been reported. In our study, we obtained a sensitivity of $78 \%$ and specificity of $100 \%$ by visual analysis of dipyridamole loading thallium-201 imaging. This result is similar to that reported in previous clinical studies. We also performed the WR-25 to estimate the ischemic heart disease, and obtained a regional sensitivity of $96 \%$ and specificity of $100 \%$, which were significantly better than visual analysis. In this study, we defined an abnormal washout ratio (WR) as $\mathrm{WR}<$ (mean of normals $-1 \mathrm{SD}$ ) instead of $2 \mathrm{SD}$, since the latter gave lower accuracy $(58 \%)$ than that of $1 \mathrm{SD}(97 \%)$ due to relatively large SD.

Since the left circumflex area may be distant from the gamma camera, it is often difficult to assess regional uptake accurately in this area. However, thallium-201 washout ratio analysis may enhance detection of perfusion abnormality in this area as reported previously ${ }^{28}$ and appears to give a better result than that achieved using visual analysis.

Clinical implication: Intravenous infusion of dipyridamole has been suggested as an alternative to physical exercise for myocardial perfusion imaging with $\mathrm{Tl}-2013-8$ It is presumed that the powerful coronary vasodilatory effect of this drug will greatly increase the myocardial blood flow in a region served by normal coronary vessels but not in myocardial regions served by diseased vessels, producing an inhomogeneity of blood flow that would be made evident by thallium scintigraphy. This pharmacological method to induce maldistribution of blood flow may be most useful in patients who are physically unable to perform adequate exercise.

Hemodynamic effects and adverse effects of dipyridamole: Heart rate and blood pressure changes after infusion of dipyridamole have been reported by others, $, 8,24-26$ All reported values were similar; 20 to 40 percent increase in heart rate and 4 to 10 percent decrease in blood pressure. In our study, heart rate increased by 14 beats/min $(21 \%)$ on the average, whereas systolic and diastolic blood pressure decreased by $15(12 \%)$ and 11 $\mathrm{mmHg}(14 \%)$ on the average, respectively.

Serious adverse effects of dipyridamole are rare and there have been no reports of death or myocardial infarction, although one patient is reported to have had ventricular fibrillation 27 Other adverse effects included chest pain, ST segment depression, arrhythmias, headache, gastric discomfort, nausea, vomiting and dizziness. Most of these side dffects do not require treatment. In our current study only one patient who had ST segment depression with chest pain needed to be treated with aminophylline $(125 \mathrm{mg})$, and pain was completly relieved within a few seconds. Thus, intravenous dipyridamoleloading scintigraphy is safe for nonexercise stress testing.

Advantages and limitations of dynamic SPECT: Although a rotating gamma camera has been popularly used as a SPECT device in many institutes, it is not suitable for fast dynamic scanning due to the low count sensitivity and the physical limitations of mechanical rotation of the detector. The new ringtype SPECT scanner consists of 3 detector rings with $128 \mathrm{NaI}$ crystals in each ring. It has been developed for high resolution dynamic SPECT imaging of the heart with high sensitivety and good spatial resolution. This is useful to evaluate the kinetics of Tl-201. The major disadvantage of this dynamic SPECT for clinical imaging is the lack of fine axial imaging. Furthermore, currently we can only obtain the transaxial images, and can not reconstruct the long axial images, which means we are unable to evaluate the inferior wall of left ventricle.

\section{Acknowledgment}

We acknowledge the technical assistance of $T$. Fujita and the secretarial asistance of $S$. Hanabuchi and $N$. Takemoto.

\section{REFERENCES}

1. STRAUSS HW, HARRISON K, LANGAN JK, et al: Thallium-201 for myocardial imaging: relation of thallium-201 to regional myocardial perfusion. Circulation 51: 641, 1975

2. POHOST GM, ZIR LM, MOORE RH, et al: Differentiation of transiently ischemic from infarcted myocardium by serial imaging after a single dose of thallium-201. Circulation 59: 294, 1977

3. GOULD KL: Noninvasive assessment of coronary 
stenoses by myocardial perfusion imaging during pharmacologic coronary vasodilation. I. Physiologic basis and experimental vasodilation. Am J Cardiol 41: 267, 1978

4. GOULD KL, WESTCOTT RJ, ALBRO PC, et al: Noninvasive assessment of coronary stenoses by myocardial imaging during pharmacologic coronary vasodilation. II. Clinical methodogy and feasibility. Am J Cardiol 41: 279, 1978

5. GOULD KL: Assessmint of coronary stenoses with myocardial perfusion imaging during pharmacologic coronary vasodilation. IV. Limits of detection of with idealized experimental cross sectional myocardial imaging. Am J Cardiol 42: 761, 1978

6. ALBRO PC, GOULD KL, WESTCOTT RJ, HAMILTON GW: Noninvasive assessment of coronary stenoses by myocardial imaging during pharmacologic coronary vasodilation. III. Clinical Trial. Am J Cardiol 42: 751, 1978

7. GOULD KL, SCHELBERT HR, PHELPS ME, HOFFMAN EJ: Noninvasive assessment of coronary stenoses with myocardial perfusion imaging during pharmacologic coronary vasodilation. $\mathrm{V}$. Detection of 47 percent diameter coronary stenosis with intravenous nitrogen-13 ammonia and emission-computed tomography in intact dogs. $\mathrm{Am}$ J Cardiol 43: 200, 1979

8. SCHELBERT HR, WISENBERG G, PHELPS $\mathrm{ME}$, et al: Noninvasive assessment of coronary stenoses by myocardial imaging during pharmacological coronary vasodilation. VI. Detection of coronary artery disease in human being with intravenous N-13 ammonia and positron computed tomography. Am J Cardiol 49: 1197, 1982

9. HOMMA S, GILLILAND Y, GUINEY TE, et al: Safety of intravenous dipyridamole for stress testing with thallium imaging. Am J Cardiol 59: 152, 1988

10. PEARL JD, BOUCHER CA: Diagnostic value for coronary artery disease of chest pain during dipyridamole-thallium stress testing. Am J Cardiol 61: 43,1988

11. BELLER GA, HOLZGREFE HH, WATSON DD: Effects of dipyridamole induced vasodilation on myocardial uptake and clearance kinetics of thallium-201. Circulation 68: 1328, 1983

12. BELLER GA, HOLZGREFE HH, WATSON DD: Intrinsic washout rates of thallium-201 in normal and ischemic myocardium after dipyridamoleinduced vasodilation. Circulation 71: 378, 1985

13. SCHMOLINER R, DUDOZAK R, KRONIK G, et al: Thallium-201 imaging after dipyridamole in patients with coronary multivessel disease. Cardiology 70: 145, 1983

14. LEPPO JA, ROSENCRANTZ J, BONTEMPS R, YIPINTSOI IT: Quantitative thallium-201 redistribution with a fixed coronary stenosis in dogs. Circulation 63: 632, 1981

15. LEPPO J, VOUCHER CA, OKADA RD, et al: Serial thallium-201 myocardial imaging after dipyridamole infusion: diagnostic utility in detecting coronary stenosis and relationship to regional wall motion. Circulation 66: 649, 1982

16. OKADA RD, LEPPO JA, BOUCHER CA, POHOST GM: Myocardial kinetics of thallium201 after dipyridamole infusion in normal canine myocardium and in myocardium distal to a stenosis. J Clin Invest 69: 199, 1982

17. OKADA RD, LIM HL, ROTHENDLER J, et al: Split dose thallium-201 dipyridamole imaging: A new technique for obtaining thallium images before and immediately after an intervention. $J \mathrm{Am}$ Coll Cardiol 5: 1302, 1983

18. YONEKURA Y, FUJITA T, NISHIZAWA S, et al: Multidetector SPECT scanner for brain and body: System performance and application. $J$ Comput Assist Tomogr 13(4): 732, 1989

19. YONEKURA Y, KOIDE H, MUKAI T, et al: Dynamic single photon emission computed tomography of thallium-201 with exercise loading. J Nucl Med (Abstr.) 27: 999, 1986

20. NIELSEN AP, MORRIS KG, MURDOCK R, et al: Linear relationship between the distribution of thallium-201 blood flow in ischemic and non-ischemic myocardium during exercise. Circulation 61: 797,1980

21. POHOST GM, OKADA RA, O'KEEFE DD, et al: Thallium redistribution in dogs with severe coronary artery stenosis of fixed caliber. Circ Res 48: 439,1981

22. CHU A, MURDOCK RH, JR, COBB FR: Relation beeween regional distribution of thallium-201 and myocardial blood flow in normal acutely ischemic, and infarcted myocardium. Am J Crdiol 50: 1141,1982

23. MELIN JA, BECKER LC: Quantitative relationship between global left ventricular thallium uptake and blood flow: Effect of propranolol, quabain, dipyridamole and coronary artery occlusion. $J$ Nucl Med 27: 641, 1986

24. BROWN BG, JOSEPHSON MA, PETERSEN $\mathrm{RB}$, et al: Intravenous dipyridamole combined with isometric handgrip for near maximal acute increase in coronary flow in patient with coronary artery disease. Am J Cardiol 48: 1077, 1981

25. JOSEPHSON MA, BROWN BG, HECHT HS, et al: Noninvasive detection and localization of coronary stenoses in patients: Comparison of resting dipyridamole and exercise thallium-201 myocardial perfusion imaging. Am Heart J 103: 1008, 1982

26. BONADUCE D, MUTO P, MORGANO G, et al: Effect of betablockade on thallium-201 dipyridamole myocardial scintigraphy. Acta Cardiol 39: 399, 1984

27. BAYLISS J, PEARSON M, SUTTON GC: Ventricular dysrhythmias follow intravenous dipyridamole during "Stress" myocardial imaging. $B r J$ Radiol 56: 686, 1983

28. TAMAKI N, YONEKURA Y, MUKAI T, et al: Stress thallium-201 transaxial emission computed tomography: Quantitative versus qualitative analysis for evaluation of coronary artery disease. $\mathrm{J} \mathrm{Am}$ Coll Cardiol 4: 1213, 1984 